\title{
A Commitment to Excellence from the New Editor
}

I am honored to be selected as the new editor of Pharmacological Reviews to continue in the footsteps of former editors to grow the prestige of this outstanding journal.

Pharmacological Reviews has a long and rich history. Established in 1948, the journal spawned from an idea of John Jacob Abel, the founding father of the American Society for Pharmacology and Experimental Therapeutics (ASPET), who suggested that a review journal would be a great asset to the society. He was right! Under the inaugural editorship of Louis S. Goodman, Pharmacological Reviews rapidly soared into the top tier. Pharmacological Reviews currently boasts an impact factor of 25.468 . Perhaps more important is the long citation half-life (>10) of reviews published in Pharmacological Reviews, underscoring the very high impact of articles published here. The journal has held steady in the top two ranks in its class for decades, currently ranked second for impact factor and first for citation half-life. When one considers the outstanding caliber of its stewards over the years, listed below, this perhaps comes as no surprise.

1949-1953 Louis S. Goodman
1954-1959 Otto Krayer
1960-1962 George B. Koelle
1963-1969 George H. Acheson
1970-1977 Marion De V. Cotten
1977-1981 Paul L. Munson
1982-1988 James A. Bain
1989-1994 Robert E. Stitzel
1995-2001 David B. Bylund
2001-2007 Darrell R. Abernethy
2008-2009 Ross D. Feldman
2010-2015 David R. Sibley
2016-2021 Eric L. Barker

I would like to thank Jackie Perry, senior journal operations manager for ASPET, and Dr. Martin Michel, professor in the Department of Pharmacology at the Johannes Gutenberg University Mainz, for their time in providing information about Pharmacological Reviews.

\footnotetext{
dx.doi.org/10.1124/pharmrev.121.000534.
}

Address correspondence to: Lynette Daws, Editor, Pharmacological Reviews. E-mail: pharmreveditor@aspet.org
I am very proud and excited to be the first woman to lead the journal. I have served as an associate editor for Pharmacological Reviews since 2010 and have learned much during my time under the editorships of Dr. David Sibley and Dr. Eric Barker. I plan to implement their strategies for success, but also, importantly, build upon them to continue to grow the prestige of this outstanding journal. I will ensure that Pharmacological Reviews continues to be the most contemporary and authoritative source of information pertaining to the pharmacological basis of therapeutics, which covers the intersection of multiple disciplines that are so closely interfaced, including biology, biochemistry, behavior, chemistry, genetics, immunology, microbiology, physiology, and toxicology. Pharmacological Reviews is a leading educational resource for existing and next-generation pharmacologists and biomedical researchers. I plan to do this in several ways.

First, I will continue to develop the associate editor (AE) base. A key to maintaining and growing Pharmacological Reviews' impressive impact factor and longevity of citation half-life is the great success of our AE team. We depend on them to maintain a healthy pipeline of articles. I plan to increase the diversity of the $\mathrm{AE}$ base in terms of gender, underrepresented minorities, and geographic balance and ensure there is expertise that fills every corner of the broad array of topics that we strive to cover in Pharmacological Reviews. Doing so can only serve to aid in the cultivation of a diverse portfolio of authoritative review articles from thought leaders in the field and mark Pharmacological Reviews as a truly equal opportunity journal.

Second, I will seek out reviews on new pharmacological spaces, such as new technologies, novel drug development, and advancements in therapeutics. While continuing to reinforce our commitment to authoritative reviews, I would like to intersperse timely hot topic articles, which could help to increase our impact factor.

Third, I will expand the reach of Pharmacological Reviews by getting the word out via social media platforms. I will work with my colleagues to increase traffic to these sites, as well as the number of followers. I believe an interactive presence on these platforms is a great way to increase the journal's visibility. 
Having been an AE for Pharmacological Reviews for eleven years, I am greatly committed to and invested in the continuing success of this prestigious journal. I am excited to serve as the next editor of Pharmacological Reviews and work with the outstanding ASPET staff, including Jackie Perry and Maria Pasho. I look forward to continuing to work with our dedicated and excellent team of AEs who work so hard to curate reviews that keep Pharmacological Reviews in the top tier of Pharmacology and Pharmacy journals.
I also want to hear from you, our readers and authors. Please send your thoughts, comments, and ideas to me at pharmreveditor@aspet.org. Together we can further increase the success and historical footprint of Pharmacological Reviews.
Lynette C. Daws, Ph.D Editor 